Research Article

\title{
Garment Waste Recycled Cotton/Polyester Thermal and Acoustic Properties of Air-Laid Nonwovens
}

\author{
S. Sakthivel, ${ }^{1}$ Bahiru Melese, ${ }^{1}$ Ashenafi Edae, ${ }^{1}$ Fasika Abedom $\left(D^{2},{ }^{2}\right.$ Seblework Mekonnen, ${ }^{2}$ \\ and Eshetu Solomon ${ }^{2}$ \\ ${ }^{1}$ Department of Garment Technology, FTVET Institute, Addis Ababa 190310, Ethiopia \\ ${ }^{2}$ Department of Textile Technology, Textile, Apparel and Fashion Technology Division, FTVET Institute, Addis Ababa 190310, \\ Ethiopia
}

Correspondence should be addressed to Fasika Abedom; fasikaabedom06@gmail.com

Received 18 June 2020; Accepted 14 August 2020; Published 27 September 2020

Academic Editor: Dimitrios E. Manolakos

Copyright $\odot 2020$ S. Sakthivel et al. This is an open access article distributed under the Creative Commons Attribution License, which permits unrestricted use, distribution, and reproduction in any medium, provided the original work is properly cited.

This research paper reports a study on thermal and sound insulation samples developed from garment waste recycled cotton/ polyester fiber (recycled cotton/PET) for construction industry applications. In this research work, the piece of clothing waste recycled cotton and polyester fiber is a potential source of raw material for thermal and sound insulation applications, but its quantities are limited. To overcome the above problems, apparel waste recycled cotton fiber was mixed with recycled/PET fiber in $50 / 50$ proportions in the form of two-layer nonwoven mats with chemical bonding methods. The samples such as cotton (color and white), polyester (color and white), and cotton-polyester blend (color and white) were prepared. All the samples were tested for thermal insulation, acoustic, moisture absorption, and fiber properties as per the ASTM Standard. Also, the behavior of the six recycled cotton/polyester nonwoven samples under high humidity conditions was evaluated. The sound absorption coefficients were measured according to ASTM E 1050 by an impedance tube method; the acoustics absorption coefficients over six frequencies of $125,250,500,1000,2000$, and $4000 \mathrm{~Hz}$ were calculated. The result revealed that recycled/PET/cotton garment waste nonwoven mats were absorbing the sound resistance of more than $70 \%$ and the recycled nonwoven mats provided the best insulation, acoustic, moisture absorption, and fiber properties. The recycled pieces of clothing waste cotton/polyester nonwoven mats have adequate moisture resistance at high humidity conditions without affecting the insulation and acoustic properties.

\section{Introduction}

The concern over the environment induced a large number of companies to start developing the manufacturing process using alternative materials for their products and seeking new markets. With the significant production of waste fibrous materials, different companies are looking for applications wherein waste materials may represent an addedvalue material [1-3]. Thermal insulation plays an important role in contributing to the energy savings in the building by heat gains and losses through the building envelope [4]. A study reported that effective building insulation alone will save over one hundred times the impacts of the carbon footprint from material usage and disposal, irrespective of the materials used [5]. Knitted waste can be converted into short fibers by the application of mechanical processes. A series of trials have been undertaken in the course of a research project aimed at more or less complete reuse of fibers from end-of-life textiles. First of all, knitted waste is crushed with a shredder [1]. The use of recycled polyester nonwovens has many advantages compared to conventional sound absorbers, including reduced product cost, good handling, and environmental protection. The sound absorption coefficient of the recycled polyester nonwovens was determined by a two-microphone impedance measurement tube; the determination of the noise absorption coefficient is nothing more than the absorption energy rate of the material against the incidence energy. They have determined the relationship between the acoustic absorption values measured and the nonwoven parameters including fiber 
properties and web properties [6]. A study was conducted on the sound absorbency of a novel knitted spacer fabric that can be applied to automotive interior parts and has the potential for greater sound absorbency than conventional plain knitted fabrics [7, 8]. Recently, noise absorbent textile materials, especially nonwoven structures or recycled materials, have been widely used because of the low production costs and they are being aesthetically appealing [9-11]. Recycled polyester (RPET) fiber is derived from the postconsumer waste of plastic bottles which are a potential source of raw material for reducing environmental pollution [12]. A study has been reported on the development of insulation materials from recycling cotton fiber with comparable properties as that of conventional materials [13]. In another recent study, the authors highlighted the quantity issues of alterative recycled polyester materials available in the market to meet the demand for the building sector, although recycled cotton materials are very good insulators. The absorption of sound mainly results from the dissipation of acoustic energy due to viscosity and heat conductivity of the medium. Differences in pore structure due to different fiber orientation and random arrangement of fibers produce samples with small pores and a higher amount of fiber-tofiber contact points which ends in better sound absorption properties [14]. In this study, chemically bonded nonwovens were manufactured from reclaimed fiber and tested for the sound absorption performance. The sound absorption influencing factors such as thickness, density, air permeability, porosity, and thermal conductivity were measured according to the ASTM Standard and the purpose of construction industry applications.

\section{Experimental Work}

2.1. Materials. The raw materials used in this research are "cut and sew" knitwear production waste materials. The waste materials were collected from knitwear garment industries then segregated depending on their colors and prepared for recycling to process in waste recycling machines. These wastes are then fed into the reused fabric opener machine to obtain recycled fibers. The recycled fiber is then converted into a web structure with different density by using the mechanical carding process in the carding machine to form air-laid webs, and the binder used here is polyvinyl acetate (PVA) as shown in Figure 1. The binder saturates on the surface layers and does not penetrate far in the structure which is normally quite thick.

The spray adhesive bonding is an exact measure of the number of binders applied, uniform binder distribution, and a soft fabric handle. The adhesive add-on percentage is taken care of to maintain at $20 \%$. Precaution is taken to avoid the excessive or lesser flow of adhesive through the sprayer. By the calendar roller pressure, the fibrous layer is converted into nonwoven fabric [15]. The produced recycled cotton/polyester samples such as cotton (color and white), polyester (color and white), and cotton-polyester blend (color and white) WC, CC, WP, CP, $\mathrm{WC} / \mathrm{P}$, and $\mathrm{CC} / \mathrm{P}$ samples were prepared. The preferred samples of proportions with $6-8 \mathrm{~mm}$ thick, $80 \mathrm{~mm}$ wide, and $200 \mathrm{~mm}$ long were developed to measure the sound absorption

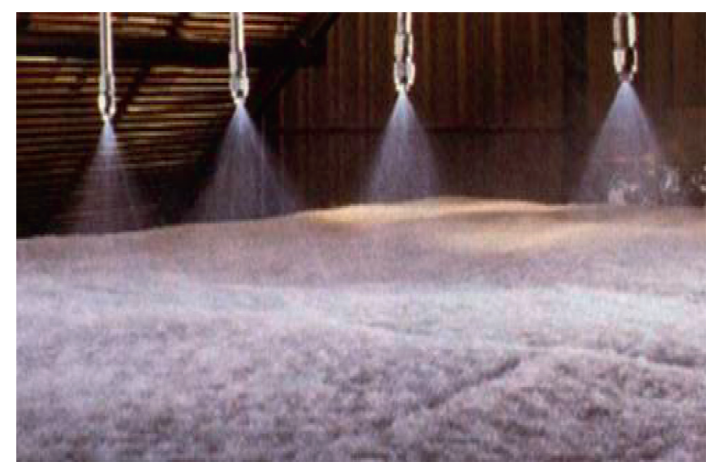

FIgURE 1: Schematic representation of adhesive bonding.

coefficient. Figure 2 shows the prepared samples of color (a) and white adhesive-bonded (b) recycled nonwovens.

The physical properties of nonwoven are fabric thickness, density, porosity, air permeability, and thermal conductivity were tested according to the ASTM standard, and physical properties were tested to measure the influence of the acoustic absorption coefficient of recycled nonwovens.

\subsection{Methods of Testing}

2.2.1. Thickness. The thickness tester is a specialized equipment to determine the thickness of nonwoven fabrics; the mean value of all the readings of thickness that were determined to the nearest $0.01 \mathrm{~m}$ is calculated, and the result is the average thickness of the sample under test. The fabric thickness was determined by ASTM D 5729 standard method.

2.2.2. Density. A study by Koizumi et al. [16] showed the increase of sound absorption value in the middle and higher frequency as the density of the sample increased. The specimen with $12 \mathrm{~cm}$ diameter and $80 \mathrm{~cm}^{2}$ areas were cut out randomly and weighed. Average of 20 observations was taken for each sample and expressed in $\mathrm{kg} / \mathrm{m}^{2}$. The density was calculated by using the following relationship:

$$
\text { density }=\frac{\mathrm{Wt}}{\mathrm{kg} / \mathrm{m}^{3}} \text {, }
$$

where $w$ is the weight of the sample per unit area, determined following the standard method ASTM D 3776. $\mathrm{m}=$ mass, and $V=$ volume. The SI unit of density is $\mathrm{kg} / \mathrm{m}^{3}$. Water of $4^{\circ} \mathrm{C}$ is the reference $\rho=1000 \mathrm{~kg} / \mathrm{m}^{3}=1 \mathrm{~kg} /$ $\mathrm{dm}^{3}=1 \mathrm{~kg} / \mathrm{l}$ or $1 \mathrm{~g} / \mathrm{cm}^{3}=1 \mathrm{~g} / \mathrm{ml}$.

2.2.3. Porosity. The porosity of a porous material is defined as the ratio of the volume of the voids in the material to its total volume is stated by Allard et al. [17]. The following equation defines porosity as

$$
\text { porosity }(H)=\frac{V_{a}}{V_{m}},
$$

where $V_{a}=$ volume of the air in the voids and $V_{m}=$ total volume of the sample of the acoustical material being tested. The porosity was found out with ASTM B 809. 

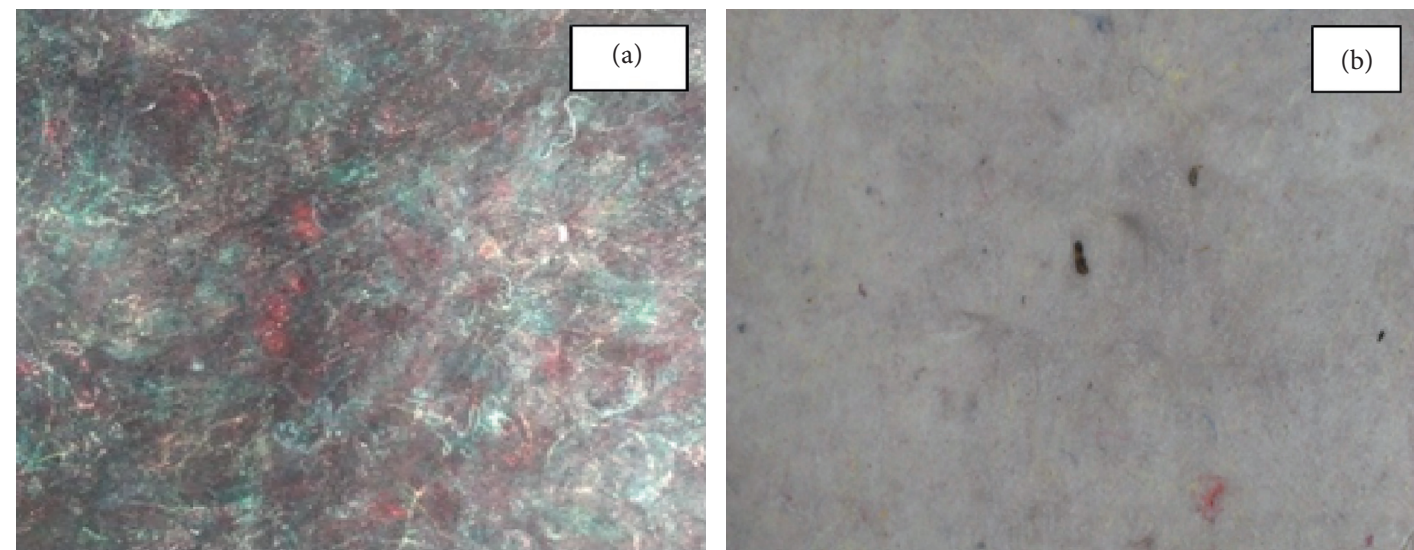

Figure 2: (a) Color and (b) white adhesive-bonded nonwoven recycled cotton/polyester samples.

2.2.4. Air Permeability. The rate of airflow passing perpendicularly through a known area of fabric is adjusted to obtain a prescribed air pressure differential between the two fabric surfaces and it is generally expressed in terms of $\mathrm{cm}^{3} /$ $\mathrm{s} / \mathrm{cm}^{2}$ calculated at operating conditions. From this rate of airflow, the air permeability of the fabric is determined under ASTM Test Method D 737.

2.2.5. Thermal Conductivity. Thermal conductivity coefficient of specimens was measured using Lee's disk method principle (Saleem [18]):

$$
\begin{aligned}
Q & =V I \\
& =a_{A} T_{A}+a_{s} T_{A}+T_{B}+A_{B} T_{B}+a_{c} T_{c}, \\
K & =\left(\frac{Q t_{s}}{T_{B}-T_{A}}\right)\left(\frac{T_{A}+2 T_{A}}{r}\left(\frac{t_{A}+t_{S}}{4}\right)+\frac{t_{S} T_{B}}{2 r}\right),
\end{aligned}
$$

where heat transfer is the measurement of the thermal energy transferred when an object having a defined specific heat and mass undergoes a defined temperature change. Heat transfer $=$ (mass) (specific heat) (temperature change). $Q=m c \Delta T$, where $Q=$ heat content in joules and $m=$ mass.

The thermal conductivity of samples was then calculated theoretically by using the Maxwell model as illustrated above where comparisons between theoretical and experimental results were accomplished. The thermal conductivity was determined following ASTM D 6343.

2.2.6. SEM Analysis Test. Morphological analysis was performed as per the ASTM D 256 Standard using a JEOL SEM instrument, on cryogenically fractured surfaces of nonwoven samples. The developed nonwovens' fractured surfaces after tensile testing are examined using a scanning electron microscope (SEM) JEOL JSM-6480LV as shown in Figure 3.

2.2.7. Measurement of Sound Absorption Coefficient. The normal incident sound absorption coefficients $(\alpha)$ were measured according to the ASTM E 1050-10 Standard test method by using an impedance tube as shown in Figure 4, which was kindly provided by Automotive Research and Testing Center (ARTC, Taiwan). When a sound wave is an incident on a material, it can be absorbed, reflected, and transmitted by the material; all three phenomena are possible depending upon the types of materials. Absorbing the incident sound wave is an effective way to control the noise.

The frequency ranges used for the measurement were $50-4000 \mathrm{~Hz}$. The frequency range was divided into three different classes: low $(50-1000 \mathrm{~Hz})$, medium $(1000-2000 \mathrm{~Hz})$, and high $(2000-4000 \mathrm{~Hz})$ ranges. Ten readings were taken randomly from each sample for evaluating acoustic properties. The sound resistance or insulation by the recycled nonwoven fabric samples can be calculated by the following derivation by Teli [19] and Sengupta [20]:

$$
\mathrm{SR} \%=\frac{\mathrm{dB}_{\mathrm{wos}}-\mathrm{dB}_{\mathrm{ws}}}{\mathrm{dB}_{\mathrm{wos}}} \times 100,
$$

where SR is the sound reduction, $\mathrm{dB}_{\text {wos }}$ is the sound level without sample, and $\mathrm{dB}_{\mathrm{ws}}$ is the sound level with sample.

\section{Results and Discussion}

3.1. Sound Absorption Property. One of the objectives was to obtain superior sound absorption property in the samples in addition to the thermal insulation property. The garment waste recycled cotton/polyester samples such as cotton (color and white), polyester (color and white), and cotton-polyester blend (color and white) were prepared. The physical properties of the recycled nonwovens have the following results as shown in Table 1.

All developed recycled nonwoven samples showed better sound absorption properties in the overall frequency range $(50-4000 \mathrm{~Hz})$. Sound absorption coefficients $\left(\alpha_{c}\right)$ of the samples in various frequency ranges are shown in Figure 5. The sound absorption depends upon the thickness of the material amongst other factors [21, 22]. The reason can be attributed to the fact that the kinetic energy of the incident sound wave gets converted to a low level of heat energy when it passes through a thicker structure. 


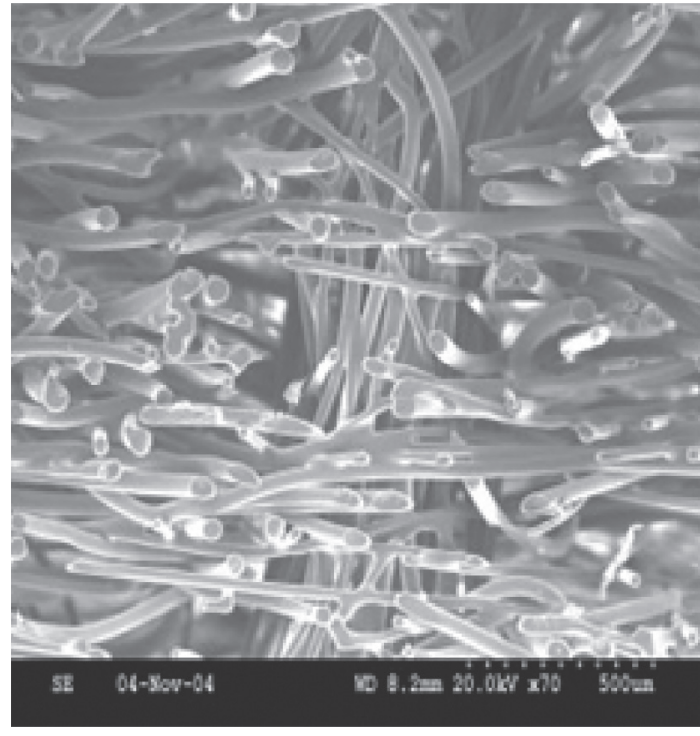

(a)

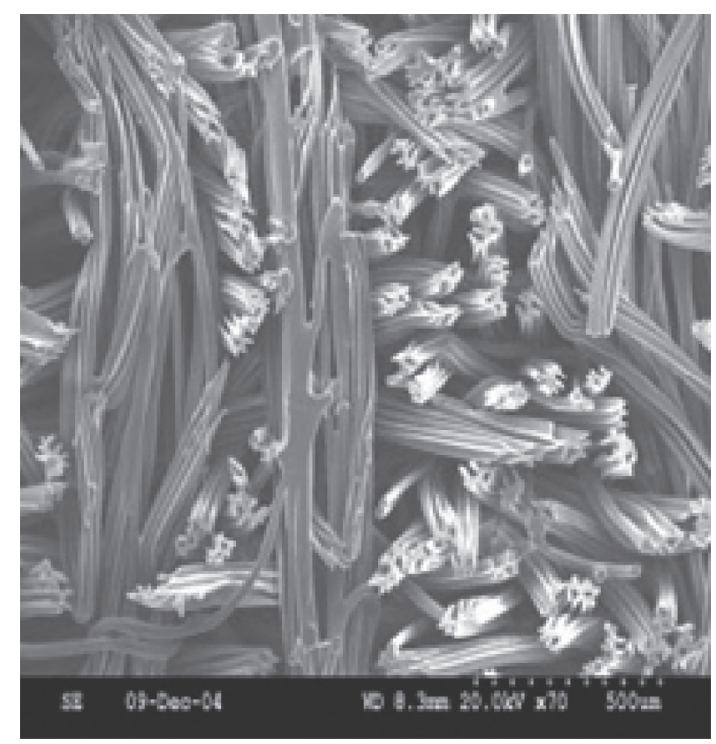

(b)

FIGURE 3: SEM image of recycled cotton/polyester nonwoven fibers.

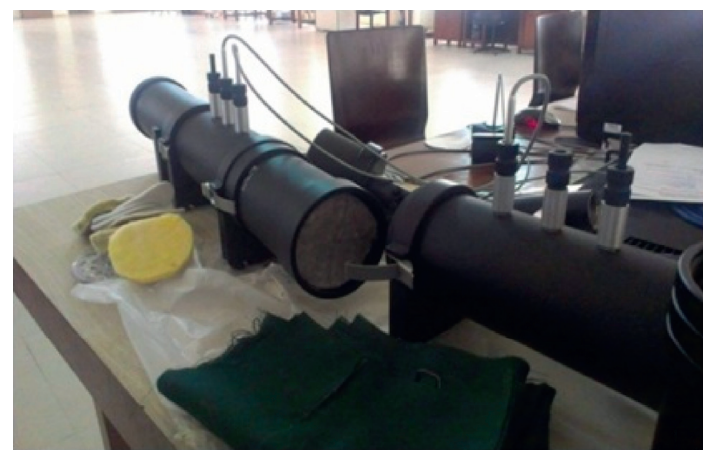

FIGURE 4: Impedance tube measurement setup.

Thicker structure absorbs sound waves by causing frictional loss between sound wave and fiber, thereby dampening the effects of the propagating sound wave. Another factor was the tortuosity component. Recycled cotton/polyester-based nonwoven samples can be observed that while frequency increases, the sound absorption coefficient (SAC) of all samples WC, CC, WP, CP, WC/P, and $\mathrm{CC} / \mathrm{P}$ also increases. Similarly, while thickness increases, the sound-absorbing performance also increases. At the highest frequency of $4000 \mathrm{~Hz}$, the SAC values of WC, CC, WP, CP, $\mathrm{WC} / \mathrm{P}$, and $\mathrm{CC} / \mathrm{P}$ are $0.4,0.68,0.4,0.65,0.55$, and 0.72 , respectively. The calculated average SAC values of WC, CC, $\mathrm{WP}, \mathrm{CP}, \mathrm{WC} / \mathrm{P}$, and $\mathrm{CC} / \mathrm{P}$ which are $0.156,0.312,0.182$, $0.331,0.232$, and 0.361 also reveal the same. Fibers interlocking in nonwovens are the frictional elements that provide resistance to acoustic wave motion. To design a recycled nonwoven web to have a high sound absorption coefficient, porosity should increase along with the propagation of the sound wave [23]. The recycled nonwoven porous structure possessed excellent performance for the absorption of high-frequency sound waves, especially above $4000 \mathrm{~Hz}[16,24]$.
3.2. SEM Analysis. Figure 4 shows the SEM image of reclaimed nonwoven fabric from which the perimeters are measured with Scalex Plan Wheel XLU. The recycled cotton/ polyester fibers' nonwoven samples are measured three times, and the final average values were taken as a fiber perimeter. The surface area of the fibers was calculated by multiplying the perimeter and the total fiber length in the fabric. The surface area of the nonwoven fabrics of $25 \times 4$ was obtained as per the ASTM Standard ASTM E 2809. The same finding was observed by $[17,25]$.

3.3. Influence of Thickness. In this study, sound absorption in porous materials was concluded as low-frequency sound absorption has a direct relationship with thickness. This study shows a high increase of sound absorption at low frequencies, as the material gets thicker, the sound absorption property decreases as shown in Figure 6. However, at higher frequencies, thickness has an insignificant effect on sound absorption. The results revealed that the thicker the material, the better sound absorption values on the middle value of the thickness of the sample. The color cotton/ polyester nonwoven $\mathrm{CC} / \mathrm{P}$ with a thickness of $13.1 \mathrm{~mm}$ results with an average SAC of 0.361 which is higher than CC, WC, WP, CP, and WC/P nonwoven fabrics. When the thickness of recycled nonwoven is less than $3.5 \mathrm{~mm}$, little sound absorption is achieved; if the thickness is more $9.03 \mathrm{~mm}$, best sound absorption is achieved. The same finding was experimented by Shoshani and Yakubov [23].

3.4. Influence of Density. Figure 7 shows that as the density increases, the sound absorption coefficient of the sample increases. A study by Koizumi et al. [16] showed an increase of sound absorption values in the middle and higher frequency as the density of the samples was increased. When there is an increase in areal density, there is increase in sound 
TABle 1: Physical properties of air-laid recycled nonwovens.

\begin{tabular}{lccccc}
\hline Sample ID & Thickness & Density $\left(\mathrm{g} / \mathrm{cm}^{3}\right)$ & Porosity & Air permeability $\left(\mathrm{CC} / \mathrm{S} / \mathrm{C} \mathrm{m}^{2}\right)$ & Thermal conductivity $(\mathrm{W} / \mathrm{mK})$ \\
\hline WC & 12 & 0.144 & 0.897 & 34.5 & 0.123 \\
CC & 12.8 & 0.15 & 0.891 & 35.6 & 0.126 \\
WP & 13.1 & 0.162 & 0.884 & 37.8 & 0.129 \\
CP & 13.2 & 0.168 & 0.898 & 38.9 & 0.13 \\
WC/P & 12.9 & 0.167 & 0.893 & 35.9 & 0.127 \\
CC/P & 13.1 & 0.174 & 0.888 & 36.4 & 0.128 \\
STDEV. & 0.4416 & 0.0115 & 0.00534 & 1.589 & 0.0025 \\
\hline
\end{tabular}

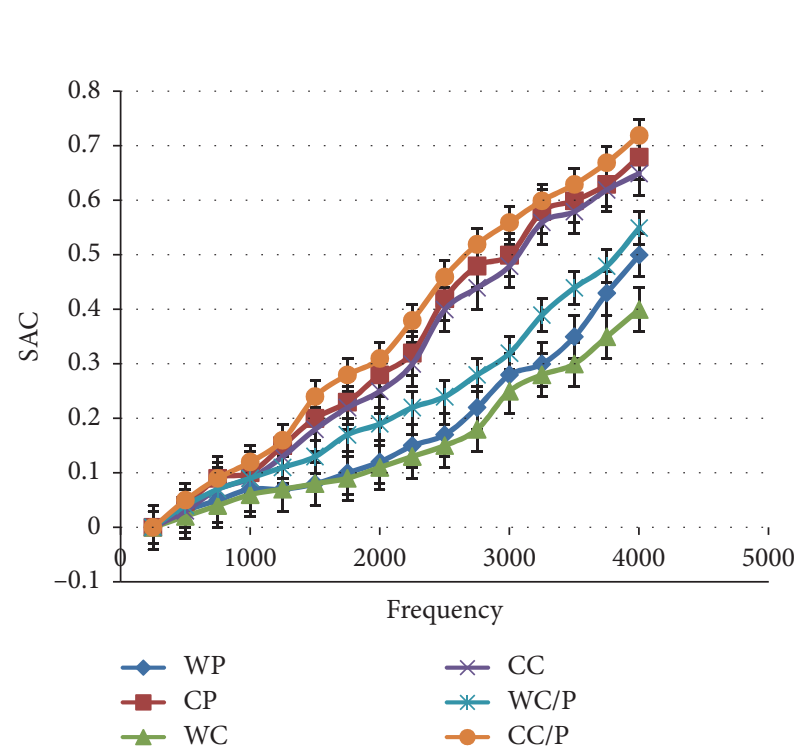

FIGURE 5: Variation of sound absorption coefficient with frequency.

absorption coefficient for cotton, polyester, and cotton/ polyester blend nonwovens. The colored materials have more density than white material due to the dying molecule content in the colored material.

The energy losses increase as the surface friction increases; thus, the sound absorption coefficient increases. Less dense and more open structure absorbs the sound of low frequencies of $500 \mathrm{~Hz}$. Denser structure performs better for frequencies above than $2000 \mathrm{~Hz}$. It reveals that the increase in density directly increases the SAC. Colored nonwoven which has a difference in density of $0.03 \mathrm{~g} / \mathrm{cm}^{3}$ while the white nonwoven depicts $24 \%$ increases in SAC. Color and white polyester nonwoven having the difference in density of $0.08 \mathrm{~g} / \mathrm{cm}^{3}$ depicts $32 \%$ increase in mean SAC. Cotton-polyester nonwoven has the difference of density $0.025 \mathrm{~g} / \mathrm{cm}^{3}$ with increases in mean SAC of 0.361 . The number of fibers increases in thickness per unit area when the apparent density is large. The same results were obtained by Wang and Torng [24].

3.5. Influence of Porosity. The porosity of a porous material is defined as the ratio of the volume of the voids in the material to its total volume stated by Allard et al. [17]. Porosity $(H)$ is given by

$$
\operatorname{porosity}(H)=\frac{V_{a}}{V_{m}},
$$

where $V_{a}=$ volume of the air in the voids and $V_{m}=$ total volume of the sample of the acoustical material being tested.

Figure 8 shows the influence of porosity on sound absorption of recycled cotton/polyester-based nonwoven upon being color and white. Samples' values are 137.74, 136.56, 142.56, 139.56, 140.56, and 138.97; the results exposed that when comparing the porosity and microspores, the microspores satisfy the diffusion sound waves. The SAC of the porous materials was highly dependent on the permeability of the materials. Less porosity and less air permeability of the samples permit the sound frequency lesser amount at lowfrequency level, but at a higher frequency, the sound enters the fine pores and experience friction between the fibers and adhesiveness, thus performing with higher absorption of sound energy.

3.6. Influence of Airflow Resistance. Figure 9 shows the relationship between specific airflow resistance and sound absorption coefficient. It can be inferred that higher airflow resistance always gives better sound absorption values. The sound absorption property was influenced by a high increase in airflow. With a high increase of airflow resistance and an increase in density of fabric, the sound absorption property is also highly affected. The airflow resistance of the color nonwoven is about $35.6-38.9 \mathrm{cc} / \mathrm{s} / \mathrm{cm}^{2}$ with SAC of 0.31 to 0.36 .

It is clear that where the fabric density increased, the airflow resistance decreased due to increased resistance to airflow caused by the consolidation of the web, but also increases the short fiber content which will occupy the air voids. The color polyester sample has the highest airflow resistance value with the $\mathrm{SAC}$ of 0.33 , which is greater than that of WC, CC, WP, CP, WC/P, and CC/P; the same result was obtained by Teli [19], Fera [26], and Sengupta [20]. It can be inferred that higher airflow resistance always gives better sound absorption values.

3.7. Influence of Thermal Conductivity. The thermal insulation properties of the samples were measured in terms of the thermal conductivity. The thermal conductivities of various samples are shown in Figure 10. The better the thermal conductivity, the better the insulation property.

Low values of the thermal conductivity imply higher resistance to conduction of the heat through the material. With the increase in temperature, the thermal conductivity 


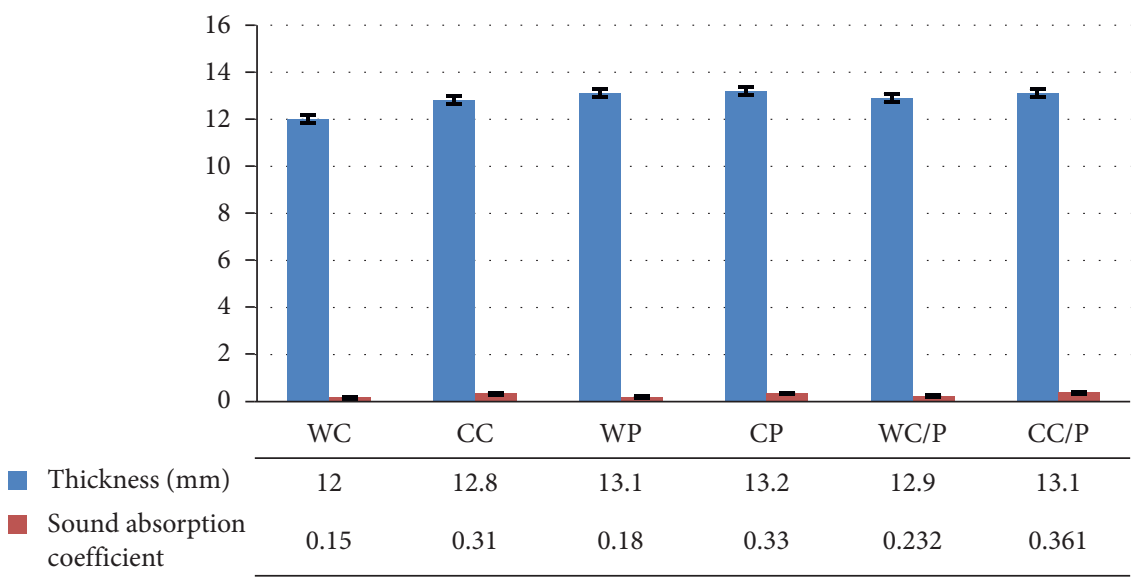

FIGURE 6: Influence of thickness on sound absorption coefficient.

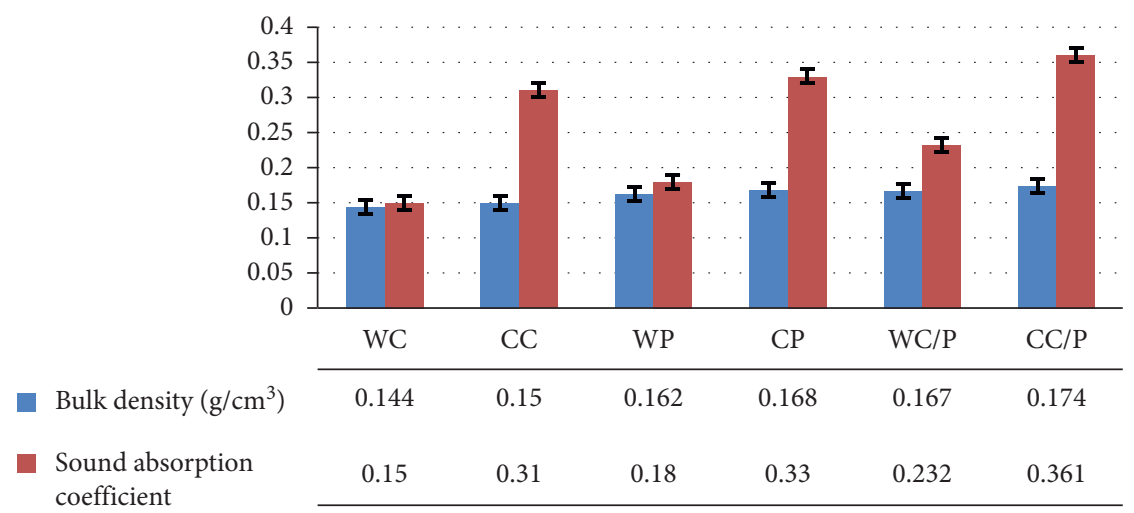

FIGURE 7: Influence of density on sound absorption coefficient.



FIGURE 8: Influence of porosity on sound absorption coefficient.

increases for all samples. Two-layer mats with $50 \%$ recycled cotton fiber along with $50 \%$ recycled fiber provided one of the best insulation properties. These results showed that it is possible to develop samples that show similar thermal conductivity as that of $100 \%$ recycled cotton and polyester fiber. The thermal conductivity for the color polyester material is about $0.13 \mathrm{~W} / \mathrm{mK}$, which has $\mathrm{SAC}$ of 0.33 which is higher than that of the $\mathrm{WC}, \mathrm{CC}, \mathrm{WP}, \mathrm{CP}, \mathrm{WC} / \mathrm{P}$, and $\mathrm{CC} / \mathrm{P}$. These samples were suitable for roof ceiling insulation applications in a building. The study has been conducted in [22].

3.8. Sound Resistance Performance of the Recycled Cotton/ Polyester Nonwovens. The chemically bonded nonwovens while tested for the sound resistance with $30 \mathrm{~dB}$ to $70 \mathrm{~dB}$ showed that the increase in the number of the layer increases the sound resistance. The average sound resistance 


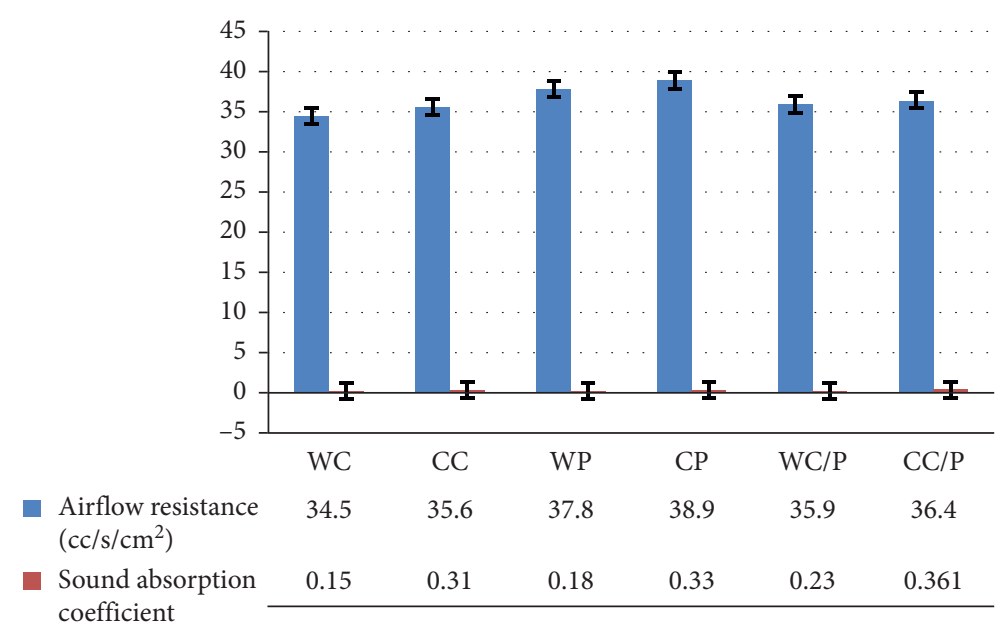

Figure 9: Influence of airflow resistance on sound absorption coefficient.

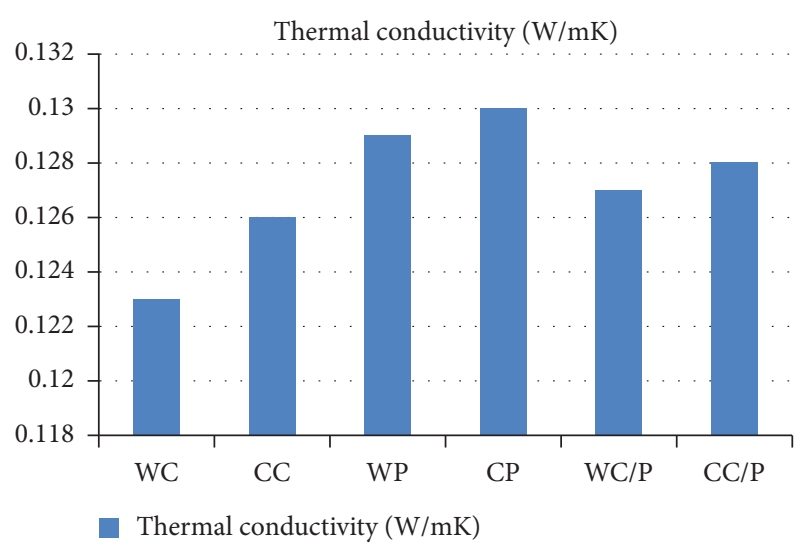

Figure 10: Influence of thermal conductivity.

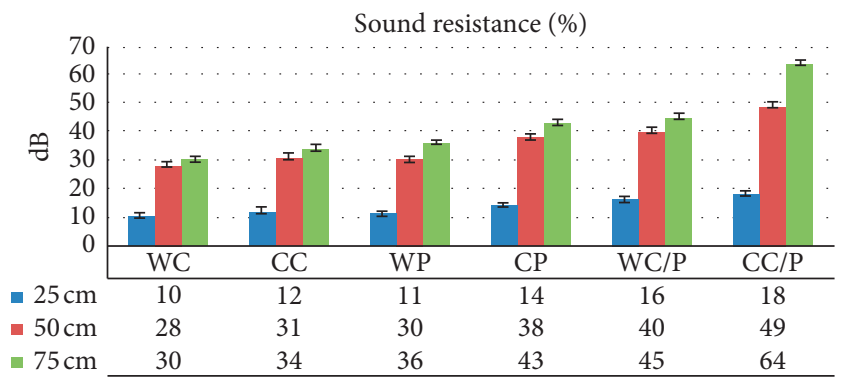

FIGURE 11: Sound resistance performance of recycled cotton/ polyester nonwovens.

percentage values for the three-decibel values are shown in Figure 11.

The nonwovens of recycled color and white cotton, color and white polyester, and color and white cotton-polyester blend show approximately $15 \%, 27 \%$, and $35 \%$ sound resistance with fabric to source distance of $25 \mathrm{~cm}, 50 \mathrm{~cm}$, and $75 \mathrm{~cm}$. The reclaimed fibers' nonwovens of color and white cotton, color and white polyester, and color and white cotton-polyester blend showed approximately 17\%, 33\%, and $42 \%$ sound resistance with fabric to source distance of
$25 \mathrm{~cm}, 50 \mathrm{~cm}$, and $75 \mathrm{~cm}$. These results also reveal that the sound resistance increases the distance between the fabric and the source increases as stated by [20].

\section{Conclusion}

The automotive and building interiors made up of recycled fibers are in potential market growth. The recycled fiber nonwoven as thermal insulation and acoustic absorption material were developed by using the fibers recycled from the waste fabrics of cotton (color and white), polyester (color and white), and cotton-polyester blend (color and white) collected from the garment industries. The nonwovens are tested for acoustic absorption by ASTM E 1050. It is observed that polyester fiber nonwoven has the highest absorption coefficient in lower frequency levels and higher frequency levels. The recycled polyester nonwoven fabrics are having high total surface area, which is influenced by the denier and cross-sectional structure of the fibers in the nonwoven fabrics. Recycled polyester/cotton mats (CC and $\mathrm{CC} / \mathrm{P}$ ) showed the best thermal insulation and acoustic absorption. $\mathrm{CP}$ and $\mathrm{WC} / \mathrm{P}$ nonwoven mats were absorbing more than $70 \%$ of the incident noise $(50-4000 \mathrm{~Hz})$. There were no significant changes in the thermal insulation and acoustic properties of the recycled nonwoven mats when evaluated under high humidity conditions. Similarly, while thickness is increased, sound-absorbing performance of polyester samples $\mathrm{WP}, \mathrm{CP}$, and $\mathrm{CC} / \mathrm{P}$ also increases, at the highest frequency of $4000 \mathrm{~Hz}$. The SEM images of fibers are detached from the resin surface due to poor interfacial bonding. Pulled-out fibers are visible for composites with 5 wt.\% fiber content and $3 \mathrm{~mm}$ length. However, the composite with $15 \mathrm{wt}$. \% fiber and $12 \mathrm{~mm}$ length shows good matrix/fiber adhesion. Hence, it is concluded that the nonwoven made of recycled polyester with its closer structure and higher sound-absorbing percentage of $72 \%$ is much suited for interiors in building and automotives. The cotton (color and white), polyester (color and white), and cotton-polyester blend (color and white) are also having sound absorption percentage of $73 \%$ is much suited for 
interiors in sound absorption of $76 \%$ and $82 \%$ at $4000 \mathrm{~Hz}$. The major application of these developed nonwoven products may be suggested for floor covering and wall coverings.

\section{Data Availability}

No data were used to support this study.

\section{Conflicts of Interest}

The authors declare that they have no conflicts of interest regarding the publication of this paper.

\section{References}

[1] https://www.cheric.org/research/tech/periodicals/doi.php?art_ seq $=1043451$.

[2] D. Bhatia, A. Sharma, U. Malhotra et al., "Recycled fibers: an overview," International Journal of Fiber and Textile Research, vol. 4, pp. 77-82, 2014.

[3] A. Roznev, "Recycling in textiles," Supply Chain Management, vol. 19, no. 1, pp. 1-20, 2011.

[4] D. M. S. Al-Homoud, "Performance characteristics and practical applications of common building thermal insulation materials," Building and Environment, vol. 40, no. 3, pp. 353-366, 2005.

[5] A. C. Schmidt, A. A. Jensen, A. U. Clausen, O. Kamstrup, and D. Postlethwaite, "A comparative life cycle assessment of building insulation products made of stone wool, paper wool and flaxflax," The International Journal of Life Cycle Assessment, vol. 9, no. 1, pp. 53-66, 2004.

[6] Y. Lee and C. Joo, "Sound absorption properties of recycled polyester fibrous assembly absorbers," AUTEX Research Journal, vol. 3, pp. 78-84, 2003.

[7] T. Dias, R. Monaragala, P. Needham, and E. Lay, "Analysis of sound absorption of tuck spacer fabrics to reduce automotive noise," Measurement Science And Technology, vol. 18, no. 8, pp. 2657-2666, 2007.

[8] Y. Liu and H. Hu, "Sound absorption behavior of knitted spacer fabrics," Textile Research Journal, vol. 80, pp. 19491957, 2010.

[9] J. Zach, A. Korjenic, V. Petránek, J. Hroudová, and T. Bednar, "Performance evaluation and research of alternative thermal insulations based on sheep wool," Energy and Buildings, vol. 49, pp. 246-253, 2012.

[10] M. S. Sakthivel, T. Ramachandran, M. G. Archana, J. Ezhilanban, and V. M. S. Sivajith Kumar, "Sustainable nonwoven fabric composites for automotive textiles using reclaimed FIBRES," International Journal of Engineering Research and Development, vol. 4, pp. 11-13, 2012.

[11] M. D. Stanciu, I. Curtu, C. Cosereanu et al., "Research regarding acoustical properties of recycled composites," in Proceedings of the 8th International DAAAM Baltic Conference Industrial Engineering, Tallinn, Estonia, 2012.

[12] K. W. Corscadden, J. N. Biggs, and D. K. Stiles, “Sheep's wool insulation: a sustainable alternative use for a renewable resource?" Resources, Conservation and Recycling, vol. 86, pp. 9-15, 2014.

[13] B. Wierman, "New frontiers for fiber-based noise control solutions," Sound and Vibration, vol. 44, p. 14, 2010.

[14] W. O. Ogunbowale, P. Banks-lee, K. A. Bello et al., "The effects of fiber type and layering structure on the acoustical absorptive properties of nonwoven," Continental Journal Applied Sciences, vol. 6, pp. 19-30, 2011.

[15] Y. Shoshani, "Studies of textile assemblies used for acoustic control," Technical Textiles International, vol. 2, no. 3, pp. 32-34, 1993.

[16] T. Koizumi, N. Tsujiuchi, and A. Adachi, "The development of sound absorbing materials using natural bamboo fibers," High-Performance Structure and Composites Book, WIT Press, Southampton, UK, 2002.

[17] J. F. Allard, C. Depollier, and P. Guignouard, "Free field surface impedance measurements of sound-absorbing materials with surface coatings," Applied Acoustics, vol. 26, no. 3, pp. 199-207, 1989.

[18] F. M. Saleem, Thermal and mechanical investigation of fiberreinforced epoxy, Ph.D. thesis, Mechanical Engineering Department, University of Technology, Baghdad, Iraq, 2006.

[19] M. D. Teli, "Efficacy of nonwoven materials as sound insulator," Indian Journal of Fiber and Textile Research, vol. 32, 2007.

[20] S. Sengupta, "Sound reduction by needle-punched nonwoven fabrics," Indian Journal of Fiber \& Textile Research, vol. 35, pp. 237-242, 2009.

[21] F. Asdrubal, Survey on the Acoustical Properties of New Sustainable Materials for Noise Control, Euronoise, Tampere, Finland, 2006.

[22] M. Küçük and Y. Korkmaz, "The effect of physical parameters on sound absorption properties of natural fiber mixed nonwoven composites," Textile Research Journal, vol. 82, no. 20, pp. 2043-2053, 2012.

[23] Y. Shoshani and Y. Yakubov, "Numerical assessment of maximal absorption coefficients for nonwoven fiberwebs," Applied Acoustics, vol. 59, no. 1, pp. 77-87, 2000.

[24] C.-N. Wang and J.-H. Torng, "Experimental study of the absorption characteristics of some porous fibrous materials," Applied Acoustics, vol. 62, no. 4, pp. 447-459, 2001.

[25] S. Santhanam, M. Bharani, and S. Temesgen, "Recycling of cotton and polyester fibers to produce nonwoven fabric for functional sound absorption material," Journal of Natural Fibers, vol. 16, pp. 3-4, 2018.

[26] T. F. Fera, "Manufacture of reclaimed fiber non-woven for sound absorption," Journal of Material Sciences \& Engineering, vol. 7, p. 5, 2018. 